\title{
Christine Tauber \\ Die Flucht ins Decorum: Jacob Burckhardts neapolitanische Kapitulation
}

\section{Antipatbien von Anbeginn}

Jacob Burckhardts neapolitanische Kapitulation war die Folge einer ästhetischen Niederlage. Am 9. August I846 schrieb er aus Venedig an Wilhelm Wackernagel: »Ach wie gern möchte ich Ihnen noch was von der Reise schreiben! aber es reicht nicht mehr. Neapel war herrlich, aber ich gehe nicht wieder unter das dortige Lumpenpack. ${ }^{1}$ Und sechs Tage später an Gottfried Kinkel in Bonn: »Neapel habe ich für immer gesehen, man kriegt mich ohne ganz besondere Gründe nicht mehr dorthin, obschon das Land ein Paradies ist. $\ll^{2}$ Diese beiden, jeweils in sich widersprüchlichen Aussagen spiegeln ein Dilemma: Burckhardt kam, kurz gesagt, mit Neapel nicht klar. Vielleicht liegt es an dieser Unfähigkeit zur Aneignung, daß der sonst ganz und gar nicht kommunikationsschwache Burckhardt so gut wie keine rekonstruierbaren »Realien « seiner zwei Neapel-Aufenthalte hinterlassen hat. Wenig ist in späteren Briefen, in zwei Jugend-Gedichten und in den Kunstnotizen von den Reisen dokumentiert: Besichtigungen der Sammlungen im Palazzo degli Studi; ein Besuch im Palazzo Reale in Portici; ein Ausflug nach Capri; ein DonizettiAbend im Teatro di San Carlo 3 ; ein Besuch bei einem Bekannten im Vicolo Donna Regina; ein anderer bei dem Berliner Studienfreund und orthodoxen Protestanten Albrecht Wolters, der sich beim Seidenfabrikanten John Major als

I Jacob Burckhardt, Briefe. Vollständige und kritisch bearbeitete Ausgabe, hrg. v. Max Burckhardt, 1o Bde., Basel 1949-1986, Bd. III, 30 .

2 Brief vom 15.8.1846 aus Venedig, Briefe (wie Anm. I), III, 32 .

3 Vgl. den Brief vom I.9.1876 aus Turin: "Gestern war die Traviata viel geringer als in Mailand, heute ist riposo, und morgen Lucia, welche mir von dieser Truppe gesungen, kann gestohlen werden. Und dazu heißt
Hauslehrer verdungen hatte. Den Archäologen Gervasio, für den ihm Bachofen einen Empfehlungsbrief schrieb, hat Burckhardt wohl nie aufgesucht. Das ist fast alles, was über Burckhardts vita di tutti i giorni in Neapel bekannt ist. Es gibt keine Zeichnungen wie sonst von den Reisen, nur gedächtnisstützende Skizzen in den Reisenotizheften. Briefe aus Neapel, falls sie existiert haben sollten, sind mit den beiden Konvoluten an den Vater und an Franz Kugler in Berlin unwiederbringlich verloren gegangen. Wir wissen nicht, wo Burckhardt gewohnt hat, nur sehr lückenhaft, wie sein Besichtigungsitinerar aussah, ja nicht einmal, ob er den Vesuv je bestiegen hat. ${ }^{4}$

Das ansonsten methodisch eher bedenkliche Argumentieren ex silentio ist in diesem Fall das einzig mögliche und sogar legitime, da vor allem das Verschweigen aufschlußreich für Burckhardts ästhetischen Urteilskanon ist. Bei der ersten Reise von I 846 dominiert noch sehr stark das aus dem Norden "Mitgebrachte«, I853 hat sich das klassizistisch-italienisch geprägte Urteil bereits stärker verfestigt. Burckhardts ästhetische Topographie ist vielschichtig, dennoch leicht absteckbar. Seine "Kunstlandschaften « konstituieren sich zumeist in Gegensatzpaaren, so daß für das Urteil ein Positiv-Negativ-Raster entsteht, in den das einzelne Kunstwerk eingeordnet werden kann. Für die Frührenaissance ist der »rechnende« Florentiner Kunstgeist entscheidend, davon werden im Negativen das "sinnverwirrende«

die ganz austremulierte I [Prima] Donna Antonietta Brambilla und ist vielleicht die Tochter jener Teresa Brambilla, die mich vor 30 Jahren in Neapel als Lucia alle nuvole versetzte! «; Briefe (wie Anm. I), VI, ro4f.

${ }_{4} \mathrm{Zu}$ den wenigen bekannten Fakten über Burckhardts Neapelaufenthalte vgl. in gewohnter Detailfreudigkeit Werner Kaegi, Jacob Burckhardt. Eine Biographie, 7 Bde., Basel; Stuttgart 1947-1982, v.a. Bd. III, 30-34, $455-45^{8}$. 
Venedig und das "prunkliebende " Neapel abgesetzt. Für das goldene Kunstzeitalter der Hochrenaissance dagegen ist Rom - jetzt im Gegensatz zu Florenz - normgebend, während Genua und Neapel in dieser Epoche völlig ausfallen. Neapel hat - hierin Rom vergleichbar - in Burckhardts Augen nur dann erträgliche Kunstwerke hervorgebracht, wenn es Anregungen von außen erhielt. Im Gegensatz zu Rom jedoch hat es aus diesen Importen keine eigene organische Tradition durch Integration geschaffen. "Die Fassaden Neapels stehen in jeder Beziehung um ein Bedeutendes tiefer [als die Roms]; in Florenz, Venedig und Genua herrschen die aus der vorhergehenden Periode ererbten Typen weiter «, heißt es im Cicerone ${ }^{6}$; und an anderer Stelle: »In Neapel konnte schon vor I 600 eine Missform entstehen, wie die Fassade des Gesù nuovo, mit ihrer facettirten Rustica, und um I620 eine so gedankenlose Marmorwand, wie die der Gerolomini; beide wären in Rom unmöglich gewesen. (Schon der Travertin nöthigte die Römer zu gleichmässiger Behandlung, während Neapel zwischen Marmor und Mörtel schwankt.) «7 Trotz der ständigen Versuche, sich Unbekanntes durch den Vergleich mit Bekanntem, vor allem Nördlichem, begreifbar zu machen, ist Burckhardt die Annäherung an diese unentschiedenchaotische, auch architektonisch wild wuchernde Stadt nicht gelungen. ${ }^{8}$ Bereits Goethe hatte den neapolitanischen »Höllenprudel $« 9$ in der Italienischen Reise einprägsam beschrieben, der ihm

5 Vgl. z.B. Jacob Burckhardt, Der Cicerone. Eine Anleitung zum Genuss der Kunstwerke Italiens, Basel I855, 663: "Neapel, dessen Schicksale gerade zu Anfang des XVI. Jahrh. sehr bewegt waren, verdankt vielleicht seine wenigen ganz ausgezeichneten Sculpturen nicht inländischen Kräften.

6 Cicerone (wie Anm. 5), 393.

7 Cicerone (wie Anm. 5), 372.

8 Die vergleichende Einordnung und die Suche nach Nördlichem im Süden lassen sich gut in den größtenteils unpublizierten Reisenotizen Burckhardts verfolgen, die im Staatsarchiv Basel-Stadt aufbewahrt werden: vgl. PA 207, 36b, III, 4-6, zu der »Gemeeldegallerie der Studj«: "Zingaro Große Madonna in trono mit Heiligen, sieht den florentin. und venezian. Naturalisten des XV Sec. sehr ähnl. Falten schwer und plump, einen Vorgeschmack auf das plutonische Erlebnis der nachfolgenden Vesuvbesteigung gab: »Wir fuhren auf zwei Calessen, weil wir uns als Selbstführer durch das Gewühl der Stadt nicht durchzuwinden getrauten. Der Fahrende schreit unaufhörlich: Platz, Platz! damit Esel, Holz oder Kehricht Tragende, entgegen rollende Calessen, lastschleppende oder frei wandelnde Menschen, Kinder und Greise sich vorsehen, ausweichen, ungehindert aber der scharfe Trapp fortgesetzt werde ${ }^{10}$. Und einer der besten Neapel-Kenner hat - in goethischer Tradition der metamorphotischen Überblendung von Natur und Kunst stehend - die spezifische Struktur der Stadt wie folgt umschrieben: "So erscheint die Baugeschichte Neapels als ein unaufhörlicher Zerfallsund Umwandlungsprozeß, in dem kaum je ein einheitlicher Wille das Gewordene festgehalten, kein historisches Bewußtsein das Vergangene integriert hat. Improvisationsbegabt und ganz dem Reiz des Augenblicks hingegeben, sehen wir den Neapolitaner durch die Jahrhunderte damit beschäftigt, sein Stadtbild umzudekorieren: eine ungeheure Freilichtbühne, auf der das Alte obsolet, das Neue provisorisch wirkt und nur der alles überstrahlenden Natur des Golfes Dauer zukommt. «II

Goethes Italienische Reise hatte Burckhardt zielsicher durch die Porta del Popolo nach Rom geführt; in Neapel fällt der große Weimarer Vorreisende als Vorbild aus, denn Burckhardt ist an Vulkanismus, Laven und Urpflanzen wenig

Stellungen noch zieml. leblos, aber die Köpfe ganz naturalistische Portreets, breit behandelt mehr ernst als edel. [...] Simone Papa. ganz im Styl der van Eycks; Erzengel Michael mit 2 Heil[igen] und 2 Donatoren in I Landschaft. Ist gewissermaßen alterthümlicher als Zingaro (sein Lehrer); wären nicht die Köpfe der 2 Heiligen so breit und flach behandelt, so schiene der Rest ganz van Eyckisch, bes. die Donatoren und die total $\mathrm{n}[\mathrm{ie}] \mathrm{d}[\mathrm{er}] \mathrm{l}[$ änd]ische Landschaft. S. Michael steht zwischen 3 Teufeln. Allerdings fehlt der Eycksche Farbenglanz und die Sorgfalt im Detail.

9 Johann Wolfgang von Goethe, Italienische Reise, in: Sämtliche Werke nach Epochen seines Schaffens. Münchner Ausgabe, Bd. XV, hrg. v. Andreas Beyer und Norbert Miller, München I992, 267 - hier dient der Begriff »Höllenprudel « zur Bezeichnung des Vesuvs. 
interessiert, noch weniger an mondänen Abenden bei »lockeren Prinzeßchen ${ }^{\mathrm{I} 2}$. Er kann es sich nicht leisten, wie Goethe in einer "Art von trunkner Selbstvergessenheit « $^{13}$ zu leben, denn seine beiden Neapel-Aufenthalte sind von Zeitdruck geprägt. I 846 hat er in Rom einen »Quasiruf $^{14}$ von Franz Kugler nach Berlin erhalten, wo er dessen beide kunstgeschichtlichen Handbücher überarbeiten soll; I853 macht er letzte Autopsien für den Cicerone, an dessen Redaktion er berserkerhaft arbeitet. Burckhardt hat bereits in Rom die Erfüllung all seiner ästhetischen Wünsche gefunden, Neapel wird für ihn nicht - wie zum Beispiel für Goethe, Herder, Waiblinger und viele andere - zum synästhetisch-belebenden Moment der Reise, zu einem Erlebnis, das den Reisenden für den zweiten Romaufenthalt sozusagen phänomenologisch verdirbt: Rom erscheint den drei Genannten nach Neapel als Mausoleum, als Totengruft der Antike, als »altes, übelplaciertes Kloster «"s. Wilhelm Waiblinger schreibt am 28. November I 828 aus Rom an Georg Reimer: "Seit einigen Tagen, verehrtester Freund, bin ich wieder in der stillen toten traurigen Roma, und fühlte mich, als ich durch die Porta S. Giovanni hereinzog, als ob ich in eine teure Heimat zurückkäme, wo ich einst herrliche Tage verlebt, und nun Freunde und Liebe alle zu Grab gegangen. Es wollte sich auch seither nicht schicken, daß ich recht heiter gestimmt wurde, und ich wünschte mich tausend$\mathrm{mal}$ in mein schönes wildes Capri zurück ${ }^{16}$. Am

Io Italienische Reise (wie Anm. 9), 235.

I I Christof Thoenes [unter Mitarbeit von Thuri Lorenz], Neapel und Umgebung, Stuttgart I97I (Reclams Kunstführer Italien, Bd. VI), I6.

I 2 Italienische Reise (wie Anm. 9), 395.

I 3 Italienische Reise (wie Anm. 9), 254.

I4 Briefe (wie Anm. I), III, 22.

Is Italienische Reise (wie Anm. 9), 230.

I6 Wilhelm Waiblinger, Werke und Briefe. Textkritische und kommentierte Ausgabe in fünf Bänden, hrg. v. Hans Königer, Bd. 5.I, Stuttgart 1982, 508.

I7 Ibid., SII.

I $8 \mathrm{Zu}$ Burckhardt und Winckelmann vgl. - allerdings zumeist nur referierend - Thomas Noll, Vom Glück des Gelehrten. Versuch über Jacob Burckhardt, Göttingen 1997, 270ff.; auszugsweise wiederabgedruckt
I0. Januar 1829 heißt es dann im Brief an die Eltern: "Es sind nun zwei Monate, daß ich das schöne Neapel verlassen, und mein vierteljähriger Aufenthalt in diesem irdischen Paradiese wird mir unvergeßlich süß in Erinnerung bleiben. Wer Neapel gesehen, kann nie mehr ganz unglücklich werden! So sagt unser größter Dichter, und in der Tat es hat viel Wahres. Lange stritt es in mir, ob ich es nicht für immer zu meinem Aufenthalt wählen wolle, aber zarte Familienverhältnisse, und die Arbeitslust zog mich nach Rom zurück, wiewohl ich bald wieder zurückkehren werde. Anfangs mißglückte mir alles in Rom, und ich hatte das peinigendste Heimweh nach Meer und Vesuv [...]. «17

Burckhardt ergeht es da mehr wie Winckelmann. ${ }^{18}$ Denn gerade in jenen Schriften, die aus Winckelmanns Neapelaufenthalten hervorgegangen sind - dem Sendschreiben von den Herculanischen Entdeckungen ( 1762 ) und den Nachrichten von den newesten Herculanischen Entdeckungen (I764) - zeigt dieser wenig Neigung, »die von ihm in der Kunstgeschichte einmal aufgestellte Methode« an neuen Gegenständen zu prüfen, um sie dann gegebenenfalls zu »verbessern, zu reinigen, zusammenzudrängen und vielleicht sogar teilweise aufzuheben. $\ll^{19}$ Winckelmann scheint vielmehr bemüht, sich von der »äußeren Welt « nicht von dem in Rom gefundenen System abbringen zu lassen. Das mühsam errichtete "Lehrgebäude ${ }^{20}$ der Geschichte der Kunst des Alterthums lief Gefahr, durch die Flut der herku-

unter dem Titel: Das Ideal der Schönheit - Burckhardt, Winckelmann und die Antike, in: Jacob Burckhardt und die Antike, hrg. v. Peter Betthausen u. Max Kunze, Mainz I998, 7-26.

I9 Diese Fähigkeit hatte Goethe in seinem kanonischen Text von I 805 als ein Charakteristikum des Stendalers lobend hervorgehoben: Johann Wolfgang von Goethe, Winckelmann und sein Jahrhundert, in: Sämtliche Werke nach Epochen seines Schaffens. Münchner Ausgabe, Bd.6.2, hrg. v. Victor Lange, Hans J. Becker u.a., München I988, I95-401, hier: $373 \mathrm{f}$.

20 So Winckelmann im ersten Satz der Vorrede zu seinem Hauptwerk: Johann Joachim Winckelmann, Geschichte der Kunst des Altertums, Darmstadt 1982, 9: "Die Geschichte der Kunst des Altertums, welche ich zu schreiben unternommen habe, ist keine bloße 
lanischen Neuentdeckungen unterspült zu werden. Die Chance, gänzlich neue Zeugnisse des Altertums mit eigenen Augen sehen zu können, barg immer auch das Risiko, frühere Glaubenssätze revidieren zu müssen. Gerade das malerisch-freie Prinzip konnte das soeben kanonisierte Ideal des Plastischen bedrohen. Es verwundert nicht, daß Winckelmann die Buntheit Neapels als Gegenwelt zu seiner römischen Systematik empfunden hat, daß sein plastischer Blick vom Malerisch-Überbordenden irritiert wurde. Bekanntermaßen hat er weder den Schritt nach Griechenland noch den näherliegenden auf die großgriechische Insel gewagt und konnte vielleicht nur durch diese Ausblendungen von Realität sein griechisches Ideal retten. Das »Systema der Kenntnisse des Alterthums $\ll^{21}$ durfte nicht durch neue Funde umgestürzt werden: Winckelmann vollzog ebensowenig eine herkulanische wie Burckhardt eine neapolitanische $»$ Kehre $\ll^{22}$. Wie Winckelmann reist auch Burckhardt nicht nach Sizilien und auch für ihn stellt bereits das vielfarbige Neapel im wörtlichen wie im übertragenen Sinne ein hinlängliches Polychromieproblem dar. ${ }^{23}$

Selbst die reichen Schätze der neapolitanischen Antiken können es für ihn nicht mit den in Rom besichtigten aufnehmen: Er bemängelt im Cicerone an den Skulpturen im neapolitanischen

Erzählung der Zeitfolge und der Veränderungen in derselben, sondern ich nehme das Wort Geschichte in der weiten Bedeutung, welche dasselbe in der griechischen Sprache hat, und meine Absicht ist, einen Versuch eines Lehrgebäudes zu liefern«. Vgl. auch Norbert Miller, Winckelmann und der Griechenstreit, in: Johann Joachim Winckelmann 1717-1768, hrg. v. Thomas W. Gaehtgens, Hamburg 1986, 239- 264, v.a. 254: "Es geht Winckelmann nicht um eine noch so subtile Zergliederung durch den Connoisseur, sondern um die ungeteilte Beschwörung des Gültigen noch im Zustand der Zerstörung.«

2I Johann Joachim Winckelmann, Sendschreiben von den Herculanischen Entdeckungen. Herculanische Schriften I, hrg. v. Stephanie-Gerrit Bruer u. Max Kunze, Mainz I997, S. 87. Dort spricht er von dem von ihm entwickelten "Systema«, das durch zeitgenössische Fälschungen antiker Malereien in seiner Gültigkeit und Integrität bedroht sei.
Museum immer wieder die modernen Restaurierungen und Anstückungen und hebt die von ihm verachteten Reste antiker Polychromie oder aufwendiger Materialillusionen hervor. ${ }^{24}$ Ausgerechnet »eines der wenigen Absurda der antiken Kunst«, ein »den Eros umschlingende[r] Delphin $\ll^{25}$, befindet sich in Neapel, und selbst der Farnesische Stier paßt in Burckhardts Bild vom Gewimmel dieser Stadt, weil er die »figurenreichste Freigruppe der alten Kunst ist $\aleph^{26}$ und als »Bravourarbeit $\ll^{27}$ abqualifiziert wird. Am I6. I0. I 896 schreibt er rückblickend an Wölfflin: »Im Museo von Neapel ist wohl noch die gleiche Sauordnung wie Anno 46 und Anno 53. Als einst in der Galerie vier Kerle mit großen Kehrbesen ganze Staubwolken aufwirbelten, nahm ich Einem den Besen aus der Hand, zeigte ihm wie man relativ staubfrei kehren könne [...]. (28 $^{28}$

Ordnung ins Chaos wie in die Vielfalt der italienischen Formenwelt überhaupt zu bringen, hatte sich der Cicerone zum Ziel gesetzt. Es war sicher nicht Burckhardts erleuchtetste Entscheidung, sich I 853 zur Textredaktion ausgerechnet in den Moloch Neapel zu begeben. Aber offenbar hatte sein erster Neapelaufenthalt vom Sommer I 846 für die Autopsien nicht ausgereicht, was wohl vor allem darauf zurückzuführen ist, daß Burckhardts Blick zu diesem Zeitpunkt noch nicht »ciceronegerecht« konditioniert war.

22 Vgl. Norbert Miller, Archäologie des Traums. Versuch über Giovanni Battista Piranesi, München 1978, $20 \mathrm{f}$.: "Die vertraute und gesicherte Gegenwart der Geschichte löschte in gewisser Weise das Geschichtsbewußtsein aus. Umgekehrt war es diese selbstverständliche Handgreiflichkeit des Vergangenen, die mehr noch als der arkadische Zauber der melancholisch über das Campo Vaccino oder die Campagne verteilten Trümmer einstiger Größe den von weither kommenden Künstler, Antiquar oder Dichter in Bann schlug. Die Vorerwartung und der phantastische Traum erfuhren da im Zusammentreffen mit der weihelosen, alltäglichen Präsenz des Bedeutenden und im Erleben heroischer Landschaft als Genreszene ihr Korrektiv, und aus der verwirrten Enttäuschung des ersten Augenblicks erwuchs dann jeweils - bei Anton Raffael Mengs wie bei Winckelmann, bei Johann Heinrich Füssli wie bei Hubert Robert oder Robert Adam - die schöpferische Vision einer für Gegenwart und Zukunft verbindlichen Antike«; vgl. auch Eric 


\section{Die germanische Brille}

Der erste Neapelaufenthalt Burckhardts dauert sechzehn Tage, vom i7. Juni bis zum 3. Juli i 846 . Seiner Erleichterung über die Rückkehr nach Rom am 6. Juli verleiht er durch einen Eintrag in seinen Reisepaß Ausdruck: Dort findet sich das Saturn-Sonnen-Zeichen von seiner Hand, das er chiffrenhaft für die aetas aurea verwendet. ${ }^{29} \mathrm{Be}-$ sonders erfreulich kann diese erste Neapelreise nicht gewesen sein. Kurz vor seinem Eintreffen hatte sich dort sein Berliner Studienfreund Ernst Wilhelm Ackermann umgebracht: »Und Ackermann starb 4 Tage vor meiner Ankunft. So ist denn endlich dieser Comet, der so unendlich fremdartig und interessant durch unsere Kreise zog, vor unsern Augen verglüht. Er war von Hause aus eine egoistische Natur, die Alles nur auf sich selbst bezog und ganz ungeheuer viel Lebensstoff consumirte, oder, wenn sie satt war, muthwillig verwüstete. Aber dabei welch ein Mensch! [...] Ich kann gar nicht sagen, daß ich ihn eigentlich lieb gehabt hätte, dafür war er mir von Anfang an zu gewaltig, zu sehr außer aller Linie. Zudem, was hätte er mit meiner Freundschaft anfangen können? Er überschaute noch ganz andere Leute als mich, denn das ist das Unglück des Genius: er vereinsamt den, welchem er allzumächtig innewohnt. - Und diese Natur

Maria Moormann, "... und dieser Esel ist hier das gelehrteste."Winckelmann und die antike Wandmalerei, Stendal 1995 .

23 In der Polychromiedebatte der Zeit tat sich vor allem Franz Kugler hervor. Seine Diskussionsbeiträge zur Frage der farblichen Fassung antiker Architektur und Skulptur finden sich in seinen Kleinen Schriften und Studien zur Kunstgeschichte, 3 Bde., Stuttgart I853I854, darin: Bd. I, 265-327: Ueber die Polychromie der griechischen Architektur und Sculptur und ihre Grenzen (1835); Bd. I, 327-35 I: Nachträge (I85I); Bd. I, 352-36I: Bestätigungen (I 8 52). Vgl. auch seinen Artikel "Antike Polychromie im Deutschen Kunstblatt 3, I852, I29-I3I; 137-I39; weiterhin Gottfried Semper, Vorläufige Bemerkungen über bemalte Architektur und Plastik bei den Alten, Altona I 834, und Jakob Ignaz Hittorff, Restitution du temple d'Empédocle à Sélinonte, ou l'Architecture polychrôme chez les Grecs, Paris I851. Vgl. zur Polychromiedebatte in der Kunstliteratur nach der Entdek- mußte zugleich so ungleich angelegt sein, daß ihr die Krone alles Daseins, das ruhige Gestalten, fehlte! - und zwar im Leben wie im Dichten. «30

Die Charakterzeichnung des genialischen Selbstmörders sagt viel über Burckhardts Freundschaftsverständnis, mehr aber vielleicht noch über die Formation seiner ästhetischen Vorstellungen aus. Ackermann wird hier strukturanalog gezeichnet zur späteren Charakterisierung Michelangelos im Cicerone: als der Typus des ungehemmt grenzüberschreitenden Genies, das an seiner Hybris zugrunde gehen muß. Das Zitat spiegelt einerseits Burckhardts moralische Ablehnung eines als Bedrohung für den eigenen apollinischen Lebensentwurf empfundenen Menschentypus. Andererseits stößt ihn Ackermann auch deshalb ab, weil seine Lebensbahn sich nicht wie in einem gelungenen Kunstwerk gerundet hat: Er war »zu sehr außer aller Linie», einer Linie, die bereits zu diesem frühen Zeitpunkt die Grenze der Burckhardtschen klassizistischen Ästhetik markiert, die zugleich immer auch eine Morallehre ist. Der tote Ackermann scheint für Burckhardt strukturell in das neapolitanische Chaos gepaßt zu haben, wie man auch dem Gedicht »In Neapel. Auf E. W. Ackermanns Tod, I 846 « entnehmen kann:

kung der Farbreste an den Metopen von Selinunt: Michele Cometa, Il romanzo dell'architettura. La Sicilia e il Grand Tour nell'età di Goethe, Bari 1999, v.a. $185-232$.

24 Burckhardts spätklassizistische Vorbehalte gegenüber der Vielfarbigkeit zeigen sich bereits in seinen frühen Reisenotizen von I 846 , wenn er über die Fassade des Domes von Orvieto schreibt: »der reinere architekton. Sinn litt darunter, die Polychromie seine Feindin«; PA (wie Anm. 8), 207, 36b, IV, 4.

25 Cicerone (wie Anm. 5), 536.

26 Cicerone (wie Anm. 5), 503.

27 Cicerone (wie Anm. 5), 504.

28 Briefe (wie Anm. I), X, 300.

29 PA (wie Anm. 8), 207, 36a.

30 Brief an Gottfried Kinkel, 15.8. 1846, Briefe (wie Anm. I), III, 33 . 
»Doch, wenn einst im Vesuv sich die Cyklopen regen,

Und durch die Lava quillt wildsprüh'nder Aschenregen,

Und graue Nacht die Stadt umwebt,

Und wenn in wilder Flucht die Wagen stadtwärts fliegen,

Und Scharen, halbentseelt, vor Gnadenbildern liegen,

Indes der Boden brüllt und bebt -

Und Thürme stürzen ein, es schüttert Straß' an Straße,

Laut donnernd stürmt herein vom Meer die Wogenmasse;

Es mischen sich zur Melodie

So Erd' und Meer, als wär's die letzte Nacht der Nächte,

Dann wißt: Dämonen sind's, die unterird'schen Mächte,

Und ihrem Sohne rufen sie! - «3I

Hier spricht noch der junge Burckhardt, der in romantischer Selbststilisierung als Taugenichts nach Rom reist, epigonale Gedichte verfaßt und dem Freundschaftskult seiner Bonner und Berliner Studienzeit nachhängt. In diesen spätromantischen Kontext paßt auch, daß er sich auf dieser ersten Reise vor allem mit mittelalterlichen Kunstdenkmälern beschäftigt. In seinen bislang unpublizierten Kunstnotizen zur Reise von Rom nach Florenz $z^{32}$ findet man fünf »Erinnerungen aus Neapel I 7 Juni - 3 Juli I 846 « gewidmete Seiten, die sich ausschließlich mit mittelalterlicher

3I Jacob Burckhardt, Gedichte, hrg. v. K. E. Hoffmann, Basel $1926,66$.

32 Staatsarchiv Basel-Stadt, PA (wie Anm. 8), 207, 36b; mit dem Untertitel $\mathrm{Zu}$ Florenz aus der Erinnerung niedergeschrieben.

33 Vgl. die Liste von Burckhardts Vorträgen in Bd. I4 (hrg. v. Emil Dürr) der Gesamtausgabe, hrg. v. Emil Dürr, Werner Kaegi, Heinrich Wölfflin, u.a., I 4 Bde., Stuttgart/Berlin/Leipzig 1929-I934, 508-514.

34 Burckhardt sah die Kirche noch in dem sehr verbauten Zustand vor der purifizierenden Restaurierung von 1882.

35 PA (wie Anm. 8), 207, 36b, IV, I6f.
Kunst in Neapel befassen. Hierbei scheint Burckhardts Blick, der seine kunsthistorische Prägung durch den Berliner Parteigänger deutscher Gotik, Franz Kugler, erhalten hatte, doppelt konditioniert zu sein. Zum einen hatte er kurz vor seiner Abreise, am i2. Februar i 846, einen Vortrag vor der Basler Antiquarischen Gesellschaft über »Abt Suger und die Kirche von St. Denis « gehalten und dadurch seinen Blick für gotische Chorumgänge und Kapellenkränze geschärft. ${ }^{33}$ Unter der Zwischenüberschrift »Germanische Baukunst in Neapel« heißt es dann auch entsprechend: »Wider Erwarten findet man in Neapel gothische Bauten aus angiovinischer Zeit, die zu den besten in Italien gehören. [...] San Lorenzo (ich bin nie draus klug geworden) Hat die Form einer breiten, sehr verbauten Basilica, mit flacher Decke; ${ }^{34}$ der Triumphbogen ist ein ziemlich flacher Spitzbogen. Erst mit dem Chor beginnt das Werk eines guten deutschen Künstlers; eine schöne (leider verhunzte) Chormuschel, sammt Chorumgang und Capellenkranz, völlig nach deutscher Art. «35

Die zweite Prägung, die sich hier abzeichnet und die die französische Perspektive zu überlagern scheint, geht - besonders in den Jahren vor I 848 - auf den deutsch-nationalen Freundeskreis um Gottfried Kinkel zurück. In diesem Sinne muß man wohl die Äußerungen zur »deutschen « bzw. »germanischen Baukunst « lesen, die sonst kunsthistorisch absurd erscheinen müßten, diskutiert die moderne Forschung am Chorbau von S.Lorenzo Maggiore doch viel eher einen möglichen französischen Einfluß. ${ }^{36}$ Eine natio-

36 Vgl. Renate Wagner-Rieger, Der Chor von S. Lorenzo Maggiore in Neapel, in: Actes du XIXe Congrès international d'histoire de l'art, Paris 1958 (1959), I39-I44; dies., S. Lorenzo Maggiore in Neapel und die süditalienische Architektur unter den ersten Königen aus dem Hause Anjou, in: Miscellanea Bibliothecae Hertzianae zu Ehren von Leo Bruhns, Franz Graf Wolff Metternich, Ludwig Schudt, München I96I, I3I-I43; Jürgen Krüger, S. Lorenzo Maggiore in Neapel. Eine Franziskanerkirche zwischen Ordensideal und Herrschaftsarchitektur. Studien und Materialien zur Baukunst der ersten Anjou-Zeit (Franziskanische Forschungen, 3r. Heft), Werl 1986; 
nale Parteinahme für einen genuin germanischen Stil, der der heruntergekommenen italienischen Architektur im ersten Viertel des I3.Jahrhunderts unter die Arme gegriffen habe, findet man schon - mit Berufung auf Vasari - bei Johann David Passavant in seinem anonym erschienenen, neu-deutsch religios-patriotischen Text von I 820 Ansichten über die bildenden Künste und Darstellung des Ganges derselben in Toscana. ${ }^{37}$ Die Kategorie des »Volksthümlichen « wird hier als ästhetischer Legitimationsbegriff für die nazarenische Malerei verwendet, um sie vom Vorwurf der bloßen Nachahmung italienischer Vorbilder $\mathrm{zu}$ reinigen und auf eine neue, patriotische Stufe zu heben ${ }^{3}$. In einer für die erste Hälfte des I9. Jahrhunderts typischen Argumentation verklärt Passavant das deutsche Mittelalter zur goldenen Zeit bürgerlicher Ordnung: »Das deutsche Volk! im Mittelalter so groß und herrlich, mag nun schaamroth auf den traurigen, erschlafft gesunkenen Zustand seines Landes in den letztverflossenen Jahrhunderten blicken, wo es seine Freiheit, Poesie und bildende Kunst verlor, weil

Caroline A. Bruzelius, Il coro di San Lorenzo Maggiore e la ricezione dell'arte gotica nella Napoli angioina, in: Il Gotico europeo in Italia, a cura di Valentino Pace e Martina Bagnoli, Napoli 1994, 265-277. Wie sehr Burckhardts Blick hier tatsächlich durch Projektion gewünschter Seheindrücke beeinflußt ist, zeigt die Tatsache, daß er bereits in den Reisenotizen von I 853 ganz selbstverständlich von einem französischen Einfluß ausgeht, da dann nicht mehr die "germanische" Baukunst, sondern die Antike und die Renaissance im Vordergrund seines Interesses stehen; vgl. PA (wie Anm. 8), 207, 36e, XXIX, 30: »S. Lorenzo Der Campanile gute dat[iert] ${ }^{4} 87$ frühe Renaissance - das Portal daneben noch früher. Im Capitelsaal, und in sonstigen Nebenräumen sind antike Säulen verbaut, mit stark überhöhten Bogen. Der Capitelsaal verliert durch seine neuere Bemalung seinen besten Werth. Das Gothische französisch «.

$37 \mathrm{Zu}$ Vasaris Entwicklungsschema der Kunst vgl. Giorgio Vasari, Leben der ausgezeichnetsten Maler, Bildhauer und Baumeister. Deutsche Ausgabe von Ludwig Schorn und Ernst Förster, Stuttgart; Tübingen I $832-1849$, neu hrg. v. Julian Kliemann, 6Bde., Worms I988, Bd. 2.I, Einleitung, sff. - In den $A n-$ sichten über die bildenden Künste und Darstellung des Ganges derselben in Toscana; zur Bestimmung des Gesichtspunctes, aus welchem die neudeutsche Malerschule zu betrachten ist. Von einem deutschen Künst- es ihrer nicht mehr würdig war! Doch wieder Hoffnung erregend zeigten sich unsere Schriftsteller neuerer Zeit; ein besserer Geist ist mit ihnen und durch sie erregt worden; er bewieß sich in dem gemeinsamen Kampfe für Freiheit gegen fremdes Joch und für bürgerliche Ordnung; die Würdigung dessen, was unsere Voreltern groß gemacht, wird immer herrschender, und somit steht auch zu erwarten, daß das neue Leben, welches in das Reich der bildenden Kunst gedrungen ist, auf dem deutschen Boden Gedeihen finde. $\ll 39$

Gleichzeitig mit diesem politischen Aufschwung »drang [...] in das Reich der Kunst ein neues Leben", das wiederum missionarisch Einfluß auf die barbarisierte italienische Baukunst nahm: »um so mehr da uns damals die Italiener hierin nachstanden und bei ihnen nur noch eine sehr gesunkene, nachbildende Kunst ausgeübt wurde. $\ll^{\circ}$ Der Begriff des neuerwachenden »Lebens « wurde in der Kunstliteratur der Zeit gerne verknüpft mit dem des »organischen Wachstums $\ll^{4}$, der eine bodenständige, gesunde

ler in Rom [i.e. Johann David Passavant], Heidelberg u. Speier I 820, 9, wird auf das »vortreffliche Werk des Vasari verwiesen; vgl. auch ibid., 7: »Drei Perioden gibt es nothwendigerweise in der Kunstgeschichte eines jeden Volkes, wo die Kunst ihre völlige Ausbildung erhalten hat; nämlich, die des allmähligen Emporstrebens, die der höchsten Blüthe und die des Verfalls «.

38 Vgl. Passavant (wie Anm. 37), 7 I f. und 78 f.: "Wie nun in Deutschland durch ein strenges, doch gütiges Schicksal, ein großes volksthümliches Interesse im Volke ist erweckt worden, und manchem braven Jünglinge das Streben nach etwas Tüchtigem in die Brust gelegt hat: so ist auch bei vielen Jüngern der Kunst diese Gesinnung herrschend worden. Nicht zum bloßen Spielwerk und dem Kitzel für die Sinne soll die Kunst angewendet werden [...]; sondern hauptsächlich zur Verherrlichung eines öffentlichen Lebens. Soll dieses würdig geschehen, so muß ein ernster hoher Sinn aus dem Kunstwerke sprechen, auf daß er den bessern Theil des Volkes ergreife und ihn bestärke in den Gesinnungen, welche, außer dem Kreise des Privatlebens, ein allgemeines volksthümliches Interesse erregen. «

39 Ibid., 6.

40 Ibid., 17.

4I Franz Kugler und Carl Schnaase hatten sich I 844 eine recht spitzfindige Debatte über die unterschiedlichen 
Genese von Kunst implizieren sollte. ${ }^{42}$ So schreibt Passavant über die Kunstgeschichte Deutschlands und insbesondere die deutsche Baukunst, sie habe sich "rein von fremdem Einfluß, aus eigener Fülle bis zur höchsten Ausbildung organisch entwickelt. «43 Und der dritte Abschnitt seines Textes endet dann folgerichtig mit dem Appell an die zeitgenössischen Künstler, dieser einstigen Einheit von Form und Inhalt, Volk und Kunst, Boden und Bauform nachzueifern: »Wir leben jetzo in einer Epoche gegeneinander wirkender Kräfte und der Entwicklung neuer Verhältnisse in unserm Vaterlande, wird dadurch der Sinn für ein großes öffentliches Leben immer regsamer und tritt solches endlich gediegen hervor: so dürfen die Deutschen, welche jetzo noch, wie sonst die alten Griechen und Italiener, den Sinn für eine organische Kunst vorzüglich besitzen, auch mit Zuversicht erwarten, daß die bildenden Künste wieder zu hoher Blüthe gedeihen werden; doch darin allein liegt jetzo bei uns ihr wahres Heil! «44

Diese Projektion der eigenen bürgerlichen Bedürfnisse auf das Mittelalter findet man auch bei Burckhardts kunstgeschichtlichem Mentor in Berlin, Franz Kugler,45 der I 842 volkstümelnd in einem längeren Passus seines Handbuchs der Kunstgeschichte über den neuerwachenden Bür-

Auslegungen und Anwendungen des Organismusbegriffs auf die Architektur geliefert: vgl. Kuglers Artikel im Kunstblatt 25 (I844), Nr. I7-I9 und Schnaases Erwiderung im gleichen Band des Kunstblattes, Nr. 58. - Zum Organismusbegriff und seiner ästhetischen Grundlegung bei Schelling und Schopenhauer vgl. Eberhard Drüeke, Der Maximilianstil. Zum Stilbegriff der Architektur im 19. Jahrbundert, Mittenwald I98I, v.a. 58-62. - Zum »organischen Ganzen" vgl. Georg Germann, »Das organische Ganze«, in: archithese II (1972), 36-4I, der den Wurzeln dieses Konzeptes in der Renaissance, dann bei Sulzer und Hirt nachspürt.

42 So noch Carl Schnaase im fünften Band seiner Geschichte der bildenden Künste, Düsseldorf 18 56, 37, wo er über die Genese der gotischen Architektur schreibt: »[...] alle ihre Formen [hatten] eine unmittelbare, natürliche Wahrheit [...]. Ueberdies gingen sie aus dem Volke hervor, und zwar aus einem Volke von noch sehr einfachen Sitten, das der Natur nahe stand und mit ihrer Weise der Production bekannt gersinn des I3. Jahrhunderts schrieb: »Diese Erscheinung [...] beruht auf jener freien und kräftigen Entwickelung des volksthümlichen Sinnes, der lang im Stillen genährt oder gewaltsam niedergehalten, in derselben Periode sich kräftig und entschieden bethätigte, und durch den ein vielgestaltiges, reiches und mächtiges Bürgerthum ins Leben gerufen ward. Der neue Styl der Kunst, welcher unmittelbar auf die vollendete Entfaltung des romanischen folgte und zum Theil sogar gleichzeitig mir ihr hervortrat, ist am schicklichsten mit dem Namen des germanischen Styles zu bezeichnen. Zwar gehört derselbe nicht ausschliesslich den rein-germanischen Nationen an [...]. Dennoch erkennen wir entschieden, auch bei diesen Mischvölkern, dass es der Germanismus ist, dem er seine Nahrung verdankt; dass er sich da am Lautersten und Vollendetsten ausbildet, wo der germanische Volksgeist vollkommen rein und im durchgebildeten Bewusstsein seiner Eigenthümlichkeit auftritt; und dass er ein mehr zufälliges und willkürliches Gepräge erhält, wo (wie in Italien und Südfrankreich) der Romanismus überwiegt. [...] Die Periode des germanischen Styles bezeichnet die reichste und glänzendste Entfaltung der romantischen Kunst. «46

Speziell zu S. Lorenzo in Neapel hieß es dann: »der Chor mit Umgang und Kapellenkranz [ist]

war; sie bildeten daher ein so feines Gefühl für organische Entwickelung der Form aus, wie es mit Ausnahme der Griechen kein anderes Volk gehabt hatte. Ihre Werke machen den Eindruck innerer Nothwendigkeit, sie scheinen aus dem Boden zu wachsen, wie die Erzeugnisse der Natur selbst «.

43 Passavant (wie Anm. 37), $7 \mathrm{f}$.

44 Ibid., 98.

45 $\mathrm{Zu}$ Kuglers national engagierter Gotikdeutung und seiner Polemik gegen Sulpiz Boisserée über dessen Domwerk vgl. Jens Bisky, Poesie der Bankunst. Architekturästhetik von Winckelmann bis Boisserée, Weimar 2000, 303-325.

46 Franz Kugler, Handbuch der Kunstgeschichte. Zweite Auflage. Mit Zusaetzen von Dr. Jacob Burckhardt, Stuttgart I $848,537 f$. - Burckhardt hatte offenbar zu diesem Zeitpunkt an der volkstümelnden Gotik-Deutung seines Lehrers nichts auszusetzen, da er weder ergänzend noch korrigierend in den Text der ersten Auflage des Handbuches eingegriffen hat.

47 Ibid., 594 f. 
in guter, nordischer Weise gebildet.«47 Der Künstler wird von Kugler in einen vaterländisch engagierten Bürger verwandelt, ganz im Sinne Passavants, der gerade diese Tugend an den Nazarenern besonders hervorgehoben hatte: »Dabei erkannten sie, daß ein Künstler hauptsächlich nur volksthümlich wirken soll, und verließen die fast ausschließlich üblich gewordenen Darstellungen aus der griechischen und römischen Geschichte und Mythologie, um Gegenstände zu behandeln, welche auf unsere vaterländische Geschichte und Religion Bezug haben. «48

Burckhardts Vorliebe für Gotik in Neapel findet man in - allerdings ideologiefreien - Rudimenten auch noch 1855 im Cicerone wieder, wo übrigens der Terminus des "germanischen Stils « weiterhin parallel zu dem des "gothischen " benutzt wird, ${ }^{49}$ während er dann I 863 in der Ästhetik-Vorlesung vom Begriff »Gotik « gänzlich verdrängt wird. ${ }^{\circ}$ Wie zur Bestätigung der Vermutung einer deutsch-nationalen Brille auf seiner ersten Reise verweist Burckhardt einerseits im Cicerone bei der Behandlung von S. Lorenzo politisch (und stilkritisch) korrekter auf die »mitgebrachten französischen Baumeister«, andererseits verurteilt er jetzt die sonstige neapolitanische Gotik im Vergleich zur nördlichen als unorganisch: »Diesen vereinzelten französischen

48 Passavant (wie Anm. 37), 71.

49 Cicerone (wie Anm. 5), I $24 \mathrm{ff}$.

so Jacob Burckhardt, Aesthetik der bildenden Kunst. Der Text der Vorlesung "Zur Einleitung in die Aesthetik der bildenden Kunst « aufgrund der Hss. kommentiert und hrg. v. Irmgard Siebert, Darmstadt I992, 45-50; vgl. auch die Anmerkung zum "germanischen Baustyl in Kuglers Handbuch (539): „Wir bezeichnen denselben gewöhnlich mit dem Namen des gothischen Styles, und wir dürfen keinen Anstand nehmen, dieses Wort in unsrer Sprache beizubehalten, indem hiebei nicht (wie etwa, wenn man den romanischen Styl mit dem Namen des byzantinischen bezeichnet) eine Begriffsverwirrung zu befürchten ist. An das Volk der Gothen wird Niemand bei diesem Worte denken; auch war es nicht im Entferntesten ein nationeller Bezug, was zur Einführung dieses $\mathrm{Na}$ mens Veranlassung gab. [... Ich habe in diesem Handbuch den Ausdruck sgermanisch durchgehend angenommen, theils der schärferen Distinction wegen, theils um Architektur und bildende Kunst des-
Einfluss abgerechnet hat überall das südliche Grundgefühl den Sieg behalten. Die gothischen Formen, losgetrennt von ihrer Wurzel, werden nur als decoratives Gewand übergeworfen; Spitzthürmchen, Giebel, Fensterabwerk u. dgl. sind und bleiben in Italien nie etwas Anderes als Zierrath und Redensart, da ihnen die Basis fehlt, deren Resultat und Ausdruck sie sind, nämlich das nordische Verhältniss des Raumes zur Höhe und die strenge Entwicklung der Form nach oben. « ${ }^{51}$

Die Gotik des Südens scheint zu sehr vom »Raumgefühl « der Renaissance überlagert zu sein, das ein unorganisches, da von der Antike abgeleitetes ist. Burckhardts Konzeption des Organischen aber ist mehr an der Funktionalität eines Bauwerks als an volkstümlicher Verwurzelung orientiert. ${ }^{52}$ Funktionalität wiederum wird im $\mathrm{Ci}$ cerone noch deutlich unterschieden von höchster Schönheit, die keinen Zwecken und Notwendigkeiten folgt. Daher kann auch die unorganische Frührenaissance hier nur durch ein unbedingtes Glaubensbekenntnis des Autors gerettet werden, ein Verfahren, das der ansonsten moralisch-ästhetisch so strengen Lehre von Burckhardts Genußanleitung eigentlich widerspricht: »An allen Enden offenbart sich der Hauptmangel dieses ganzen Styles: das Unorganische. [...] Wer aber auf dem

selben Styles auch mit demselben Worte bezeichnen zu können. «

s I Cicerone (wie Anm. 5), I25; als »organische« Stile im Gegensatz zum unorganischen, abgeleiteten Renaissancestil - werden im Cicerone der griechische und der gotische gekennzeichnet und somit klassizistische Antikenverehrung mit spätromantischer Mittelalterbegeisterung gepaart: "In Zeiten eines organischen Styles, wie der griechische und der nordisch-gothische waren, erledigt sich nun die Sache von selbst; eine und dieselbe Triebkraft bringt Formen und Proportionen untrennbar vereinigt hervor. Hier [in der Renaissance] dagegen handelt es sich um einen secundären Styl, der seine Gedanken freiwillig in fremder Sprache ausdrückt. « Ibid., 30I.

52 Vgl. Burckhardts Definition des Unorganischen: »Die Formen drücken nur oberflächlich und oft nur zufällig die Functionen aus, welchen die betreffenden Bautheile dienen sollen«, Cicerone (wie Anm. 5), I7 I. 
Gebiet der Baukunst nur in dem streng Organischen die Schönheit anzuerkennen vermag, hat auf dem italischen Festlande mit Ausnahme der Tempel von Pästum überhaupt nichts zu erwarten; er wird lauter abgeleitete und schon desshalb wenig organische Style vorfinden. Ich glaube indess, dass es eine bauliche Schönheit giebt, auch ohne streng organische Bildung der Einzelformen; nur dürfen letztere nicht widersinnig gebildet sein, d.h. ihren Functionen nicht geradezu widersprechen [...]. Wo ein Reiz für das Auge vorliegt, da liegt auch irgend ein Element der Schönheit; nun übt offenbar ausser den schönen, strengen Formen auch eine gewisse Vertheilung der Grundflächen (Räume) und Wandflächen einen solchen Reiz aus [...]. Ja, es werden Aufgaben gelöst, Elemente der Schönheit zu Tage gefördert, welche in den beiden einzigen streng organischen Stylen, dem griechischen und dem nordischgothischen, nicht vorkommen, und sogar nicht vorkommen konnten. «53

\section{Renaissancearabesken}

Wie Burckhardts Tagesablauf während seines zweiten, anderthalb Monate dauernden Neapelaufenthalts aussah, hat Heinrich Wölfflin überliefert: "Anno 53 - das war die Zeit, als Burckhardt am Cicerone arbeitete. Er erzählte gern, wie er sich die Arbeit damals eingeteilt habe. Früh sechs Uhr fing er an mit seinen Gängen, machte ein paar Stationen mit Caffè nero und Caffè latte, hielt aber durch bis elf Uhr, wo ein Gläschen süßer Wein genommen wurde, um

53 Cicerone (wie Anm. 5), I7rf.

${ }_{54}$ Heinrich Wölfflin, Gedanken zur Kunstgeschichte. Gedrucktes und Ungedrucktes, Basel I94I, I6I.

55 Cicerone (wie Anm. 5), 406.

56 Brief vom I2.11.1884 an Georg Finsler, Briefe (wie Anm. I), VIII, 257.

57 Briefe (wie Anm. I), III, I80.

58 Italienische Reise (wie Anm. 9), 262.

59 Ibid.; vgl. auch ibid., 25 1, Neapel, 13. März 1787: »Es geht mir gut, doch seh' ich weniger als ich sollte. Der Ort inspiriert Nachlässigkeit und gemächlich Leben, indessen wird mir das Bild der Stadt nach und nach runder. dann vor der Colazione noch zu einem Bad ins Meer zu gehen. Nachmittags machte er sich's auf seinem Zimmer bequem und schrieb gleich alle Notizen ins Reine. Gegen Abend folgte ein Ritt auf dem Maulesel (immer derselbe) auf die Höhe. So ging es Tag für Tag, sechs Wochen lang. «s4 Diesen allabendlichen Sonnenuntergangsbesichtigungen verdanken wir übrigens eine der wenigen positiven Stellen im Cicerone über Neapel, wo es über die Vomero-Villen - wenn auch mit den üblichen Einschränkungen - heißt: "Die zum Theil ältern Anlagen auf dem Vomero sind im Gartenstyl den römischen auf keine Weise zu vergleichen, auch ganz wasserlos, allein so gelegen, dass die Aussicht auch die prächtigste Einrahmung würde vergessen machen. «ss Diese, wie er schreibt, "traumhafte Herrlichkeit der Aussicht « war »die einzige Erholung die ich mir damals gönnen konnte. $«^{56}$ Aber diese Landschaft ist und bleibt nur Ort der Feierabenderholung nach getaner Arbeit - sie kompensiert nicht den fehlenden Kunstgenuß.

Chaosbändigung braucht Zeit und Kräfte. Am 31. I0. 853 schreibt Burckhardt in diesem Sinne an den Basler Ratsherren Heusler-Ryhiner: »In Neapel, Juli und August, galt es täglich mindestens acht Stunden Arbeit, und so weiter. [...] Man kann freilich etwas lernen, wenn man allen wichtigen Kunstwerken ihren geistigen Gehalt abgewinnen muß. «57 Goethe war es selbst »in der scheinbaren Verwirrung « der Stadt gelungen, "hundert Beobachtungen « zu vergleichen und $\mathrm{zu}$ ordnen, "wie der Feldmesser mit einer durchgezogenen Linie viele einzelne Messungen pro-

60 Maurizio Ghelardi hat sehr zutreffend von einer "ville stratifiée" gesprochen; vgl. id., Une promenade à Rome en compagnie de Stendhal et de Burckhardt, in: Relire Burckbardt, Paris 1997, 93-129, hier: 101; vgl. auch ibid., ro6: "un grand entrepôt, à ciel ouvert, de formes stratifiées $\ll$.

6I Vgl. den Brief an Max Alioth vom I6.4.I875 aus Rom, Briefe (wie Anm. I), VI, 32: »Im Übrigen ist Rom noch in all seinen wesentlichen Theilen, ausgenommen die Gegend um S. M. maggiore, leidlich intact, und hat noch jene ganze Fülle vornebmer architectonischer Anblicke wie keine andere Stadt auf Erden; es ist gar nicht immer die classische Schönheit des einzelnen Gebäudes welche entscheidet, sondern 
biert. $\aleph^{8}$ Der Meister der Beruhigung vollbrachte die erforderliche Ordnungsleistung - »jemehr die Straßen toben desto ruhiger werd' ich $\ll 59-$, während Burckhardts Goethe-Imitatio gerade in Neapel fehlzuschlagen scheint. Was für Burckhardt die Einmaligkeit Roms ausmachte - das Übereinander sedimentierter Zeitschichten, die räumlich gegenwärtig waren, ${ }^{60}$ der Anschauung überall versteinerte Vergangenheit präsentierten -, das kann er im neapolitanischen Schmelztiegel der Formen nicht mehr ausmachen. Hatten bereits in Rom die Kunstwerke - da omnipräsent - fast zu laut zu ihm gesprochen, so muß ihr Gebrüll in Neapel für ihn unerträglich gewesen sein. Hier findet er nicht mehr das große "Model«, das den gesamten Stadtorganismus prägt $^{61}$ und dadurch ästhetischen und historischen Genuß im erkenntnistheoretischen Sinne einer Verbindung von Anschauung, Erinnerung und Erkenntnis zugleich ermöglicht. ${ }^{62}$ Burckhardt wird von Neapel phänomenologisch überfordert, er findet keinen Schlüssel und Maßstab für diese Form des Chaos, der Überlagerung architektonischer Formen.

In Neapel greift die Strategie nicht, die in der Vierung von St. Peter erfolgreich gewesen war: Dort hatte Burckhardt gleichsam eine Mazeration der architektonischen Struktur vorgenommen, sie von allen dekorativen Zutaten befreit, um dann in diesem reinen und puren Raum höchsten zeitenthobenen Genuß zu erleben: "Wenn man sich das schlechte Nischenwerk der vier Hauptpfeiler sammt ihren Statuen hinwegdenkt und das Ganze überhaupt auf seine we-

ganze Gruppen sind wie selbstverständlich in verschiedenen Zeiten nach einem gleichartigen großen Model zusammengestellt worden. «

62 Zum Genußbegriff bei Burckhardt vgl. Wilhelm Schlink, Jacob Burckhardt über den , Genuss der Kunstwerke<, in: Trierer Beiträge II (1982), 47-55, und Christine Tauber, Jacob Burckhardts ,Cicerone. Eine Aufgabe zum Genießen, Tübingen 2000, Kap. IV: "Nachrevolutionärer Klassizismus: die ästhetischen Grundlagen des Kunsturteils im Cicerone«, v.a. I I I-I 27.

63 Cicerone (wie Anm. 5), 336; vgl. hierzu: Christine Tauber, Rechnender Geist oder Formgefühl? Jacob Burckhardt zu Florenz und Rom, in: Florenz - Rom. sentlichen Formen reduziert, so übt es einen architektonischen Zauber, der sich bei jedem Besuch erhöht $^{63}$. Im »prunkliebende[n] Neapel « ${ }^{64}$ ist Burckhardt das barocke Dekor zu übermächtig, die Kirchenfassaden sind ihm zu abschrekkend-ungegliedert, als daß sich ein distanzierend-historisierender und zugleich römisch geprägter Blick durchsetzen könnte. ${ }^{65}$ Und so wird ihm nicht römische Monumentalität zum Gegengift neapolitanischer Unübersichtlichkeit, sondern die florentinische Frührenaissance, die zwar in ihren architektonischen Formen unorganisch ist, aber den Vorteil hat, in ihren leichten und reizenden Dekorationen unbedrängend zu sein: "Der phantastische Zug, der durch diese Zeit geht, drückt sich in der ganzen Kunst durch eine oft übermässige Verzierungslust aus, welche bisweilen auch in der Architektur die wichtigsten Rücksichten zum Schweigen bringt und scheinbar der ganzen Epoche einen wesentlich decorativen Charakter giebt. « ${ }^{66}$ Über die Krypta von S. Gennaro schreibt Burckhardt dementsprechend in seinen Reisenotizen: "Das vollendetste Ren. Interieur, das südlich von Florenz vorhanden sein mag; kleine Basilica mit gleich hohen Schiffen, die flach gedeckt sind - alles Marmor. Wichtig für das innerste Gefühl der Renaissance I) Sie genügt völlig, wo sie spielen darf daher die eigentlichen Arabesken, Blumenwerk, Schilde, Bänder, Festons von schönster, leichtester Vollendung, also: alle Pilaster und Horizontalen und Vertikalen bloß Gewandung. 2) Dagegen das Organisch-architektonische sehr wenig entwickelt, das Profilirungssystem flüchtig, die tra-

Zwischen Kontinuität und Konkurrenz, hrg. v. Henry Keazor, Münster/Westf. I998, I89-208.

64 Cicerone (wie Anm. 5), 196.

65 Dennoch versucht Burckhardt in seinen Reisenotizen immer wieder dadurch an Halt im ästhetischen Durcheinander zu gewinnen, daß er vergleichende Einordnungen des Gesehenen vornimmt. Beispielsweise heißt es zu S.Lorenzo: "Im Kreuzgang das Grab des Erricus Pudericus, mit wenigen, aber höchst graziösen Arabesken im Styl der Besten von S. Greg. in Rom «; PA (wie Anm. 8), 207, 36e, XXIX, 30 f.

66 Cicerone (wie Anm. 5), r69. 
genden Glieder zu dekorativ. 3) Mit dem Figürlichen wird es hier speciell seine Bewandtniß gehabt haben. Es zeigt I gewissen mantegnesken Zopf und ist weder in den Umrissen noch in der Reliefbehandlung den Arabb. ebenbürtig. ${ }^{\ll 67}$

Burckhardt scheint bei seinem zweiten Aufenthalt in Neapel die Suche nach organischer Gotik ad acta gelegt und ganz die Frührenaissancebrille aufgesetzt $\mathrm{zu}$ haben, die auf florentinische Formen einerseits, auf spielerische Arabesken andererseits fokussiert war. Dem bedrohlichen Ernst eines neapolitanisch-barocken Angriffs auf seine ästhetischen Glaubenssätze begegnet Burckhardt, indem er ins harmlose Spiel der Frührenaissance ausweicht. So scheint in den Notizen dieser zweiten Reise ein ganzer Arabeskenteppich über die neapolitanische Realität gebreitet zu sein - auch findet man überraschend viele Skizzen von Renaissancedekorationselementen. Zu S. Chiara notiert Burckhardt: »Das Gothische sehr unbedeutend und entstellt. Innen zu beiden Seiten der Thür 2 Tabernakel: ein gothischer stark belaubt, und ein schöner Frührenaissance. Reiz dieser rein spielenden Decoration ${ }^{68}$; und zu S. Gennaro: »Am Gewölbe einfach schöne Arabesken und in der Mitte ein Salvator mundi im tondo. Sie sind nicht peruginesk. Das Geistvollste, was Neapel aus der goldenen Zeit hat. $\ll^{69}$

Auch die verspielten antiken Szenographien aus Pompeji und Herkulaneum, die der Cicerone ausführlich und würdigend behandelt ${ }^{70}$, passen ausgezeichnet in dieses Schema, herrscht doch hier ebenfalls das Erfreuliche, die Sinne Erfreuende, Leichte und Reizende vor. "Anmutig«,

67 PA (wie Anm. 8), 207, 36e, XXIX, 33-35. - Diese Passage wird dann in verkürzter Form in den Cicerone übernommen, wo die Krypta eine vergleichsweise ausführliche Würdigung erfährt: Cicerone (wie Anm. 5), 244 f.

68 PA (wie Anm. 8), 207, 36e, XXIX, I I.

69 PA (wie Anm. 8), 207, 36e, XXIX, $76 \mathrm{f}$.

70 Cicerone (wie Anm. 5), 57-64 und 720-726.

7 I Vgl. Cicerone (wie Anm. 5), 59: "An irgend eine scharf consequente Durchführung der baulichen Fiction ist nicht zu denken; das Allgemeine eines wohlgefälligen Eindruckes herrschte unbedingt vor «, und »zart«, »kindlich«, »natürlich « und »heiter « sind die mit Vorliebe verwendeten Bewertungskriterien. ${ }^{7 \mathrm{I}}$ Neapel wird gerade im Abschnitt über die Renaissancedekoration, die im Cicerone strikt von der Architektur getrennt behandelt wird, um die architektonischen Formen »rein « zu erhalten, am häufigsten erwähnt: »Als Decoratoren, ob von aussen abhängig oder nicht, wird man diese Künstler immer achten müssen, weil die Verbindung des Baulichen und des Figürlichen in ihren Werken im Ganzen eine sichere und glückliche ist, selbst wo die Figuren gering sind und nur gleichsam in den Kauf gegeben werden. $\ll^{72}$ Konsequenterweise werden die importierten skulptural-architektonischen Höchstleistungen des "florentinischen Typus' " in Neapel vor allem in diesem Dekorationsteil abgehandelt: So das Brancacci-Grabmal in S. Angelo a Nilo aus der Werkstatt Donatellos und Michelozzos; weiterhin Antonio Rossellinos Grab der Maria d'Aragona in S.Anna dei Lombardi und die Cappella Carraciolo di Vico in S. Giovanni a Carbonara. Über den laut Burckhardt von Giuliano da Maiano erbauten Triumphbogen Alfonsos schreibt er: "man lernt Giuliano nur noch als grossen Decorator kennen, zunächst im Triumphbogen des Alfons. [...] die Ornamente sind prächtig und selbst edel; die Composition aber, unorganisch und spielend, lässt das frühe Jugendalter dieses Styles nicht verkennen. «73 Giulianos Porta Capuana schließlich lobt Burckhardt als »vielleicht das schönste Thor der Renaissance. $\ll 74$

Neapolitanische Kunst ist für den Klassizisten Burckhardt nur dann gut, wenn es sich um

Cicerone (wie Anm. 5), 60: »Die gemalte Architektur ist eine von den Bedingungen des Stoffes befreite; wir wollen nicht sagen svergeistigte<, weil der Zweck doch nur ein leichtes, angenehmes Spiel ist, und weil die wahren griechischen Bauformen einen ernsten und hohen Sinn haben, von welchem hier gleichsam nur der flüchtige Schaum abgeschöpft wird. [...] die idealen Architekturen dieser alten Pompejaner [werden], selbst mit ihrer abgeblassten Farbe, auf alle Jahrhunderte Auge und Sinn erfreuen $[\ldots] \ll$.

72 Cicerone (wie Anm. 5), 245; vgl. auch ibid.: »eine ganze grosse Decoratorenschule«. 
Importkunst handelt. Er referiert daher selbst noch die absurdesten Zuschreibungen, wenn die Architektur dadurch entneapolitanisiert werden kann: So sei das Castelnuovo »angeblich nach einem Plan des Giovanni Pisano begonnen« worden. ${ }^{75}$ In der Malerei hebt Burckhardt den mäßigend-beruhigenden Einfluß der Nordländer auf die Neapolitaner hervor, der sich vor allem bei Antonio Solario, gen. lo Zingaro, und seiner Schule positiv bemerkbar mache, »welchen die Neapolitaner als den Vater ihrer Malerei zu feiern pflegen. $\star^{76} \mathrm{Zu}$ den freskierten Szenen aus dem Leben des Hl. Benedikt in SS. Severino e Sossio schreibt er: "Der Typus des hier abgebildeten Menschengeschlechtes steht zwar unter dem florentinischen und hat in Nase, Blick und Lippen etwas Stumpfes, selbst Zweideutiges. Aber eine Fülle von lebendig und bedeutend dargestellten Bildnissfiguren hebt diess auf; schön und würdig bewegen sich die Gestalten auf einem mittlern Plan, hinter welchem der bauliche oder landschaftliche Grund leicht und wohlthuend emporsteigt. [...] Nirgends bemerkt man ein Versinken in das Barocke oder ins Flaue; ein gleichmässiger edler Styl belebt Alles. «77 Und der stille Klosterhof dieser Kirche mit seiner für Neapel untypischen Malerei läßt den Reisenden kurzzeitig den äußeren Lärm und seine eigene innere Irritation vergessen: »Der stille Hof, mit der noch in ihren Trümmern herrlichen Riesenplatane, eine Oase mitten im Gewühl Neapels, erhöht noch den Eindruck. $\ll^{78}$

Was passiert, wenn Neapel versucht, eigenständige Kunst hervorzubringen, läßt sich aus Burckhardts Äußerungen zur sogenannten »ger-

73 Cicerone (wie Anm. 5), I95.

74 Ibid.

75 Cicerone (wie Anm. 5), I62.

76 Cicerone (wie Anm. 5), 844.

77 Ibid.

78 Cicerone (wie Anm. 5), 844f.; vgl. die Notizen von I $853 \mathrm{zu}$ den Zingaro-Fresken in PA (wie Anm. 8), 207, 36e, XXIX, 57-59: "Zingaro's Fresken Jedenfalls erst c[a.] I 490 gemacht; es sind schon zu viel Elemente ausgebildeter Renaissance darin, im Vergleich mit Ben. Gozzoli, dem sie sonst vorangehen müßten, wenn Zingaro I 44s starb. Die Landschaft nicht fland- manischen " Skulptur ablesen: »Wenn der Anschein nicht trügt, so hat auch hier Giovanni Pisano eingewirkt, ist aber nicht ganz durchgedrungen. So weit diese neapolitanische Sculptur von den gemeinsamen Tugenden des germanischen Styles, der Würde der Stellung, dem reinen Fluss der Draperien, dem Ernst und der Schönheit der Gesichtszüge mit bedingt ist, mag sie wohl Gefallen erregen; was ihr aber eigen, das ist eine gewisse Plumpheit und Puppenhaftigkeit, eine monotone Wiederholung derselben Motive, eine Gedankenlosigkeit, die neben den gleichzeitigen toscanischen Sculpturen arg abstechen würde. «79

In den bereits zitierten Kunstnotizen von I 846 gibt es eine noch drastischere Stelle für die Uneigenständigkeit der neapolitanischen Kunst: "Die alten neap[olitanischen] Maler vor Zingaro waren mir in Bausch und Bogen ungenießbar. Ungebührlich lang in byzantinischen Fesseln, scheinen sie sich nur ungern von diesem Faulbett aufgerafft zu haben, und selbst als sie es wagten, wollte der Lazzarone von Neapel nichts davon wissen und verlangt bis auf diesen Tag an den Aquaiuolbuden eine Metes theou in byzantinischer Manier, mit Schleier und Oliventeint, wahrscheinlich weil irgend ein Scheusal dieser Art in irgend einer Kirche Mirakel thut. $\ll^{80}$ Selbst Raffaelschüler konnten dem schlechten Einfluß der Stadt - glaubt man dem Cicerone - nicht lange standhalten: Polidoro da Caravaggio zum Beispiel entgleist hier in den »grellsten Naturalismus [...], dessen merkwürdiges Hauptdenkmal die grosse Kreuztragung im Museum von Neapel ist. Hier zuerst wird das Gemeine als wesentliche

risch, sondern schon tizianesk [...]. Die ceremoniösen, ruhigen Vorgänge besser entwickelt als die heftigen (z.B. das Aufheben des Quadersteins). Der momentane Ausdruck im ganzen trefflich, der Typus dagegen hat etwas Zweideutig napolitanisches, bes. in Nase, Blick und Lippen. Auch die jugendlichen Köpfe nicht schön, nicht florentinisch. Alles steht weit unter Dom. Ghirlandajo. [...] En tout ist es nicht das reine Renaissance Italien wie bei Ghirlandajo etc. «

79 Cicerone (wie Anm. 5), 583 f.

80 PA (wie Anm. 8), 207, 36b, IV, I 3. 
Bedingung der Energie postulirt. « ${ }^{81}$ Und die »Verwilderung « des neapolitanischen Manierismus war nur deshalb »keine so unwürdige wie in Rom und anderwärts « ${ }^{82}$, weil hier Burckhardts ästhetische Glückserwartungen ohnehin sehr niedrig gesteckt sind und daher der Verfall nicht so drastisch bemerkt wird.

Sämtliche Passagen im Cicerone über genuin neapolitanische Kunst machen den Eindruck der Unwilligkeit, was wohl auch dadurch bedingt ist, daß Burckhardt sie größtenteils pflichtmäßig aus der lokalen Guiden- und Kunstliteratur zusammengeschrieben hat. Er benutzte hierfür neben Ernst Försters Handbuch für Reisende in Italien (in der 2. Auflage von 1842) vor allem Giuseppe Galantis Nuova Guida per Napoli, e suoi contorni (1845) und Bernardo de Dominicis Vite dei Pittori, Scultori ed Architetti napoletani (174243), auf dessen Konto die Vielzahl von Fehlzuschreibungen ebenso geht wie die freie Erfindung einzelner Künstler, z.B. Giacomo de' Santis' oder der beiden Masucci.

\section{Das Ethos des richtigen Stils}

Für Burckhardt war die Entscheidung für einen Kunststil mehr als eine Geschmackssache; die Wahl der rechten Form war für ihn eine Frage der richtigen Gesinnung. Ganz im Sinne seines Gewährsmannes Séroux d'Agincourt, dem er nicht nur in der Strukturlogik von Dekadenz und Erneuerung im Entwicklungsgang der Kunst folgt, sondern auch in der Maxime, seinen Lesern in der von ihm sogenannten Kunst der Verfalls-

8I Cicerone (wie Anm. s), 939; vgl. auch PA (wie Anm. 8), 207, 36b, III, I 2: "Polidoro da Caravaggio Große Kreuztragung Christi. Den Schüler Rafaels erkennt man kaum. Er hat nur noch wenig von dem manierten [sic] Idealismus seiner Mitschüler, und neigt sich dagegen ganz entschieden einem grellen Naturalismus zu«, und PA (wie Anm. 8), 207, 36e, XXX, 16: "Die kleinern Polidoro's sind ganz widerlich affectirt «.

82 Cicerone (wie Anm. 5), 998.

83 Jean Baptiste Louis George Séroux d'Agincourt, Histoire de l'art par les monumens depuis sa décadence au IVe siècle jusqu'à son renouvellement au XVIe, 6 vol., zeit warnend $\mathrm{zu}$ benennen, »ce qu'ils doivent fuir $\ll^{8}{ }^{8}$, vertritt Burckhardt eine Vermeidungsästhetik des Unreinen. Der Architekturteil des Cicerone versucht, den Architekten des I9. Jahrhunderts wieder ein Bewußtsein für "constructive Ehrlichkeit und Gründlichkeit « ${ }^{84} \mathrm{zu}$ vermitteln, indem er sie auf ein Zeitalter der Architekturgeschichte - nämlich die Frührenaissance - zurückverweist, in dem die Architekten trotz künstlerischer Freiheit in der Formenwahl die Ethik des richtigen Bauens noch beherzigten. ${ }^{85}$ Der Akt künstlerischer Formgebung, der in der Moderne zur individuellen Gewissensentscheidung wird, fordert die Kardinaltugend der temperantia als ästhetisches Kriterium. Der gute moderne Künstler mißbraucht seine neugewonnene Freiheit nicht zu Willkürakten, fällt nicht der Mode und dem - gerade für Neapel charakteristischen - Luxus anheim, sondern bringt bei äußerster Ökonomie der Mittel ein Maximum an Harmonie und Schönheit hervor. Als Kunst, die Selbstbeschränkung in den Mitteln noch beherrschte und gerade darin Höchstes leistete, wird die mittelalterliche Malerei in Neapel im Cicerone zur Kontrastfolie für die von Burckhardt wenig geschätzten barocken Skulpturen in der Cappella San Severo. Als positives Gegenbild nennt er die Fresken der GiottoNachfolge in der Incoronata: »Bisweilen wurde aber auch auf ganz besondere Art mit der Gewandung gekünstelt. Eine der unvermeidlichen Sehenswürdigkeiten Neapels sind die drei von allen Neapolitanern (und auch von vielen Fremden) auf das höchste bewunderten Statuen in der

Strasbourg; Londres I823, vol. I, V [Discours préliminaire]: "Conduit par le même désir [de présenter aux artistes, dans l'Histoire de l'Art des Anciens, les principes de l'Art même], et à-peu-près par les mêmes circonstances, relativement à l'Art moderne, dans l'entreprise que je forme de continuer l'histoire, dont ce savant [Winckelmann] a traité la première partie, j'espère être aussi de quelque utilité à ceux qui professent les arts, mais par une route opposée et sans doute moins agréable: il leur a montré ce qu'ils doivent imiter, je leur montrerai ce qu'ils doivent fuir. C'est ainsi qu'à Sparte, l'ivresse mise sous les yeux des enfans, leur en inspirait l'horreur." 
Capelle der Sangri, Duchi di S. Severo [...] Von Corradini ist die ganz verhüllte sog. Pudicitia [...]; ein Weib von ziemlich gemeinen Formen, die sich vermöge der künstlichen Durchsichtigkeit der Hülle weit widriger aufdrängen, als wenn die Person wirklich nackt gebildet wäre. [...] Und bei all der Illusion ist der geistige Gehalt null, die Formengebung gering und selbst elend. [...] Wer von da unmittelbar zur Incoronata geht, kann mit doppeltem Erstaunen sich überzeugen, mit wie Wenigem das Höchste sich zur Erscheinung bringen läßt. ${ }^{86}$

Die strenge Observanz und der asketische Umgang mit den Kunstmitteln werden hier zum Stilprinzip erhoben. Das Maßvolle ist das Ausgeglichene, im Gleichgewicht Gehaltene, in kein Extrem Verfallende, Geordnete. Der enthaltsame Zug dieser Ästhetik zeigt sich deutlich in den Kriterien für ein gelungenes Kunstwerk: »Streng und gut « (Cic., I 22), "ganz einfach und schön« (Cic., 264), von »ernster« (Cic., I89) und »einfacher Pracht« (Cic., 20I) ist die Kunst, deren Genuß Burckhardt sich und seinen Lesern zugesteht. Hierin mag man ein Nachwirken seiner calvinistischen Erziehung sehen, deren Wirkmächtigkeit er sich nicht entziehen konnte allen apotropäischen Verurteilungen des bilderfeindlichen Hauptpropagators der "Zweiten Reformation« zum Trotz.

So muß sich der charaktervolle Künstler der Renaissance im Verzicht üben, in der Entsagung vom Prunk in einer »weislich gemässigten « (Cic., 2 Io) dekorativen Behandlung, muß stets bestrebt sein, »möglichst Weniges in möglichst grossen

84 Cicerone (wie Anm. s), 301.

85 Hierzu und zum folgenden vgl. Tauber (wie Anm. 62), $246 \mathrm{ff}$.

86 Cicerone (wie Anm. 5), 696; an der entsprechenden Stelle im Malereiteil des Cicerone (ibid., 765) heißt es dann unter dem Kolumnentitel »Das höhere Pathos «: »Wenn man aber wissen will, mit wie wenigem sich ein grosser, für jene Zeit erschütternder Eindruck hervorbringen liess, so betrachte man [...] das >Sacrament der Busse ; fast entsetzt wendet sich der Priester von der beichtenden Frau ab, während die Büsser verhüllt und gebückt von dannen ziehen«; vgl. PA (wie Anm. 8), 207, 36e, XXIX, 7If.: "Jedenfalls
Formen« zu geben (Cic., 310). Es verwundert nicht, daß gerade Neapel an »vollständigen Bauten der Blüthezeit moderner Baukunst « ${ }^{87}$ äußerst wenig aufzuweisen hat. Die wenigen Renaissancebauten, die Burckhardt mit großer Anstrengung sucht, behandelt er dann auch besonders ausführlich in seinen Reisenotizen. So zeichnet er akribisch den Fassadenaufbau des heutigen Palazzo Marigliano (damals Palazzo Alice, Strada S. Trinità) in sein Notizheft und schreibt dazu: »Ganz vortreffliche Früh Renaissance mit 2 kleinern untern und I großen obern Fensterreihe. Die Pilaster unten Compos[it], oben corinth[isch]; die untern cannelirt, die obern nicht. Die Wandflächen innerhalb derselben immer noch besonders eingerahmt. - Zarte Gliederungen, bes. der Fenster, mit Eierstab ausgelegt. Diese Renaiss[ance] Neapel eigen, nicht so arabeskenreich wie die lombardische. ${ }^{88}$

Von diesen wenigen Lichtblicken gelungener Frührenaissancearchitektur abgesehen verfügt Neapel über umso mehr Gebäude desjenigen Stils, der im Cicerone pauschal mit einem Verdikt belegt wird: Der Barock wird Burckhardt zum Gegenbild der Renaissance, in der sich Ethik und Ästhetik im hervorragenden Künstler noch vereinten. ${ }^{89}$ Ein Stakkato der Mißgunst schlägt auf diese Kunstperiode nieder: Die Formen verselbständigen sich im ausgehenden 16 . und beginnenden i 7. Jahrhundert, gleiten den Künstlern aus den Händen und geraten vor Burckhardts tadelndem Blick zu einer Mischung aus Hexensabbath und Jüngstem Gericht: „Oberhalb der Gesimse beginnt [...] der Raum, in welchem die

Giotto's Geist und Wichtigkeit. Echt monumentaler Raumsinn; höchste Deutlichkeit der facta «.

87 Cicerone (wie Anm. 5), 244.

88 PA (wie Anm. 8), 207, 36e, XXIX, I6f.

$89 \mathrm{Zu}$ Burckhardts Stellung in der Barockforschung des I9. Jahrhunderts vgl. Hans-Harald Müller, Barockforschung: Ideologie und Methode. Ein Kapitel deutscher Wissenschaftsgeschichte I870-1930, Darmstadt I973, v. a. 29-48, und Else Padtberg, Die Beurteilung der Barock-Architektur. Ein Beitrag zur Geschichte der kunstgeschichtlichen Methode, Diss. Münster I927, v. a. 3 ff. u. I $2 \mathrm{ff}$. 
entfesselte Decoration ihre Triumphe, bisweilen auch wahre Orgien feiert. « ${ }^{\circ}$ Das kindlich-harmlose Spiel der Frührenaissancedekoration wird im Barock - der »Zeit der entarteten Kunst « ${ }^{91}-$ zur verschlagenen List pervertiert. ${ }^{22}$ In sublimierter Form werden moralisierende über ästhetische Kriterien geblendet: »Selten [...] ist es mit dem Ausdruck der Functionen ernstlich gemeint. Vielmehr bekommen die einzelnen Formen ein von allem Organismus unabhängiges, später ein krankhaftes Leben. [...] es sind Fieberphantasien der Architektur.«93 Unreinheit und Krankheit werden hier zu sichtbaren Zeichen des Verwerflichen. "Wahrhaft lehrreich « kann die Dekoration des Barock nur im Negativen sein, als Menetekel für zeitgenössische Architekten, die hier prototypisch die Auswirkungen einer »übelverstandenen Freiheit « ${ }^{4}$ studieren können.

Zugleich muß es "gebildeten Architekten «95 gelingen, das Gute in der Formenwelt des Barock, das bisweilen vereinzelt zu finden ist, in der vergleichenden Betrachtung herauszudestillieren: »Man wird fragen: wie es nur einem Freunde reiner Kunstgestaltungen zuzumuthen sei, sich in diese ausgearteten Formen [des Barockstyles] zu versenken, über welche die neuere Welt schon längst den Stab gebrochen? Und woher man nur bei der grossen Menge des Guten in Italien Zeit und Stimmung nehmen solle, um auch an diesen späten Steinmassen einige mögliche Vorzüge zu entdecken? Hierauf ist zu antworten, wie folgt. Wer Italien nur durchfliegt, hat vollkommen recht, wenn er sich auf das Allerbeste beschränkt. Für diejenigen, welche sich einige Zeit gönnen, ist es bald kein Geheimniss mehr, dass der Genuss hier bei weitem nicht bloss in dem Anschauen vollkommener Formen, sondern grösserntheils in einem Mitleben der italienischen Culturgeschichte besteht, welches die

90 Cicerone (wie Anm. 5), 386.

91 Cicerone (wie Anm. 5), I73.

92 Die Gefahr dieser Pervertierung deutete sich für Burckhardt bereits in der antiken Dekorationsmalerei an: »Unläugbar ist in diesem ganzen pompejanischen Schmuckwesen wie in der Architektur schon Vieles, was der Ausartung, dem Barocken angehört. Nur schönern Zeiten vorzieht, aber keine Epoche ganz ausschliesst. Nun ist es nicht unsere Schuld, dass der Barockstyl ganz unverhältnissmässig vorherrscht und im Grossen den äussern Eindruck wesentlich bedingt, dass Rom, Neapel, Turin und andere Städte mit seinen Gebilden ganz angefüllt sind. Wer sich irgend eines weitern Gesichtskreises in der Kunst rühmen will, ist auch dieser Masse einiger Aufmerksamkeit schuldig. Bei dieser Beschäftigung des Vergleichens wird man vielleicht auch dem wahren Verdienst gerecht werden, das manchen Bauten des fraglichen Styles gar nicht abzusprechen ist, obwohl es ihnen bisweilen in Bausch und Bogen abgesprochen wird. $\ll 96$

Der analytisch unscharfe Begriff des »Mitlebens « der »Culturgeschichte« verweist erneut auf ein emotionales Ausweichen in der Argumentation: Was Burckhardt im Bereich der Ästhetik unbedingt ablehnen muß, um das System nicht zu gefährden, kann er in dem hiervon streng getrennten Bereich der Kulturgeschichte doch zulassen und sogar würdigen. Hier deuten sich erste positive Ansätze zur Einschätzung barocker Architekturformen an, die vorerst nur untergründig-emotional zugestanden werden, später dann aber präziser beschreibend in formale Kriterien der lebendigen Formentransformation von der Renaissance zum Barock einfließen. Erst diese Umdeutung des Prinzips der organischen Metamorphose der Formen ermöglichte Burckhardt in den 7oer Jahren eine eindeutige positive Neubewertung der Barockarchitektur, wie sie sich in dem bekannten Brief an Max Alioth vom 5.4. I875 aus Rom als explizites Bekenntnis des Spätberufenen niederschlägt: "Mein Respect vor dem Barocco nimmt stündlich zu und ich bin bald geneigt, ihn für das eigentliche Ende und Hauptresultat der leben-

muss man sich hüten, gleich Alles dahin zu rechnen, was nicht dem Kanon der griechischen Säulenordnungen entspricht, denn auch das scheinbar Willkürliche hat hier sein eigenes Gesetz, welches man zu errathen suchen muss «; Cicerone (wie Anm. 5), 65.

93 Cicerone (wie Anm. 5), $369 \mathrm{f}$

94 Cicerone (wie Anm. 5), 390. 
digen Architectur zu halten. Er hat nicht nur Mittel für Alles, was zum Zweck dient, sondern auch für den schönen Schein. Worüber einst mündlich Mehreres. «97 Aber es ist eben der römische, nicht der neapolitanische Barock, der diese Konversion ermöglicht.

Wer daher vom Cicerone eine Anleitung zum Genuß neapolitanischer Barockarchitektur und -malerei erwartet, wird enttäuscht. Selbst Vanvitelli mit seinem sich dem Barockklassizismus zuneigenden, fast »römischen« Raumkonzept wird nicht hinlänglich gewürdigt. Die Reggia in Caserta »bekennt « $^{9}$ Burckhardt, nur von außen gesehen zu haben, und ihre Fassade nennt er in einem Atemzug mit der perhorreszierten des Palazzo Pitti, bei deren Anblick er sich gefragt hatte, »wer wohl der weltverachtende Gewaltmensch sei, der mit solchen Mitteln versehen, allem bloss Hübschen und Gefälligen so aus dem Wege gehen mochte? «99 Burckhardts neapolitanische Kapitulation läßt sich wohl am deutlichsten dadurch illustrieren, daß er den Bau der SS. Annunziata im Cicerone nicht behandelt. So werden zwar - in erneutem charakteristischen Ausweichen in die Renaissance-Dekoration - die »ungemein reichen Sacristeischränke der Annunziata ${ }^{100}$, selbst das nicht sehr bedeutende Portal "an dem Bau neben der Annunziata « ${ }^{\text {IOI }}$ lobend hervorgehoben, Vanvitellis grandioser Innenraum jedoch wird mit keinem Wort erwähnt. Und auch Cosimo Fanzago wird nur als einer der Geringeren unter den Dekoratoren genannt, ${ }^{102}$ als Architekt dagegen fast völlig übergangen, obwohl man gerade hier ein besonderes Interesse Burckhardts an dessen spezifischer ZentralbauTypologie hätte erwarten können.

Goethe hatte in Neapel eine bislang ungekannte Einheit von Kunst und Leben genußvoll kennengelernt. In der Italienischen Reise hieß es

95 Cicerone (wie Anm. 5), 367.

96 Ibid.

97 Briefe (wie Anm. I), VI, 2 I; an diese Vorstellung einer lebendigen Formverwandlung konnte später Heinrich Wölfflin anknüpfen.

98 Cicerone (wie Anm. s), 368.

99 Cicerone (wie Anm. s), 177. dementsprechend: »Auch die neapolitanische Malerschule begreift man nur zu Neapel. «103 Wie anders klingt da das Urteil Burckhardts, der sie als »blosse Decorationsmalerei « ${ }^{104}$ abqualifiziert, da sie für ihn gänzlich aus »Virtuosen der Schnellmalerei «' ${ }^{\text {Ios }}$ besteht: »Bei Caravaggio und den Neapolitanern steht Zeichnung und Modellirung durchgängig um eine beträchtliche Stufe tiefer, da sie sich auf ganz andre Wirkungsmittel glauben verlassen zu dürfen. So gemein überdiess ihre Formen sind, so wenig kann man doch im einzelnen Fall darauf bauen, daß sie wirklich aus dem Leben gegriffen seien « - und dies wäre die Minimalanforderung an den ansonsten von Burckhardt verurteilten Naturalismus. Aber dies ist noch nicht alles, was der Autor des Cicerone den neapolitanischen Barockmalern vorzuwerfen hat: "in ihrer Gemeinheit sind sie nur zu oft auch allgemein. Der gewissenhaften Bilder sind in dieser Schule überhaupt wenige. Von Luca Giordano abwärts fällt die Zeichnung der neapolitanischen Schule dem liederlichsten Extemporiren anheim. «106 Giordano selbst wird nicht ganz so negativ beurteilt, weil er zu harmlos sei, um eine tatsächliche Bedrohung für die Kunst darzustellen. Seine Scheinhaftigkeit ist dem leichten Spiel der Renaissancearabesken vergleichbar: "L. Giordano: Semiramis vertheidigt Babylon; eins seiner sorgfältigern Bilder: Schein momentaner Kraft und Schein lebendigen Colorites, doch wirklich eine sehr tüchtige Palette. [...] Man mag ihn doch von allen des XVIIIJh. am liebsten, auch lieber als Cortona. Der Schein des Lebens, die napolitan. Süßigkeit der Köpfe (wie Volkslieder und Arien) der angenehme Mangel an jedem Ernst und jeder Tiefe; seine liederliche Anspruchslosigkeit neben Salvator Rosa. In der großen Kreuzabnahme und Grablegung hat er sich bemüht innig zu sein und giebt gutmüthige

Ioo Cicerone (wie Anm. 5), 266.

IOI Cicerone (wie Anm. 5), 247.

102 Cicerone (wie Anm. 5), 245.

I03 Italienische Reise (wie Anm. 9), 23 I.

ro4 Cicerone (wie Anm. 5), roro.

ios Cicerone (wie Anm. s), Ior 8.

Io6 Cicerone (wie Anm. 5), ror 2 f. 
alte Marinari (nicht Zigeuner wie Caravaggio und Ribera). «107

Beim »gewissenlosen «108 Lanfranco jedoch, der an anderer Stelle auch »der gemalte Bernini ${ }^{109}$ heißt, verurteilt Burckhardt kompromißlos dessen »zuerst schüchterneres, bald frecheres Improvisiren. «110 Und über Riberas Pietà schreibt er schließlich: »Spagnoletto's Hauptbild, die Kreuzabnabme im Tesoro von S. Martino zu Neapel ist in den Linien unangenehm, was man allerdings über der Farbe und dem ergreifenden, obwohl auf keine Weise verklärten Schmerz übersehen kann. Dieses Gebiet des Ausdruckes und Affectes, welchem die moderne Malerei so vieles opfert, müssen wir nun nach Inhalt und Grenzen zu durchforschen suchen. «II Bezeichnenderweise sind sowohl die Passagen über Barockarchitektur ${ }^{112}$ als auch diejenigen über barocke "moderne "Malerei ${ }^{{ }^{113}}$ im Cicerone nicht wie sonst nach Schulen geordnet, sondern die einzelnen Kunstwerke werden in einer sachlichen Gliederung jeweils als Belegstücke für bestimmte Aufgaben (z.B. Marterbilder, Ekstasenmalerei oder Visionen) herangezogen.

"Modern « ist Neapels Kunst in Burckhardts Kategorienbildung, weil sie sich nicht unter seinen edel einfältigen Imperativ ästhetischer und ethischer Mäßigung beugt. Über Solimena schreibt er in seinen Reisenotizen: »Solimena

Io7 PA (wie Anm. 8), 207, 36e, XXX, 2f. [zum Museo Borbonico].

I08 Cicerone (wie Anm. 5), 1042.

Io9 Cicerone (wie Anm. 5), I037.

I 10 Cicerone (wie Anm. 5), Io42.

I I Cicerone (wie Anm. s), ro26; vgl. auch PA (wie Anm. 8), 207, 36e, XXIX, 6r: »Ribera: die Propheten in den Bogenfüllungen; für ihn gut an sich. Aber er will wirklich sein und das Auge glauben machen, daß in jenem Raum wirklich ein Mensch sitze; und Consorten wiederholen ihre Motive beständig - warum ist es specifisch widriger als wenn die Schulen des XIV und XV Jh. und die Alten dasselbe thun? - Weil der Ausdruck ein subjectiver ist und also nur für Imal gültig wäre. $\aleph^{114}$ Das Schöne aber muß Ewigkeitsgeltung haben. Subjektivität ist ein Zeichen von Modernität in der Kunst, und sie ist für Burckhardt stets bedrohlich, da der moderne Künstler seiner Ansicht nach dazu neigt, die ihm zugestandene Freiheit zu Willkürakten zu nutzen, die sich den heiligen Kunstgesetzen entziehen. Demnach müssen ihm die neapolitanischen Barockmaler und -architekten als bedrängende Inkarnationen des modernen Künstlertums erschienen sein. Die Klassifikation ihrer Kunstwerke »nach Aufgaben« wird somit als Zügelungsinstrument gegen ihre potentiell regelsprengende Einbildungskraft benutzt. ${ }^{115}$

Das erklärte Ziel der Italienreise Burckhardts von 1846 war es gewesen, der nördlichen politischen und ästhetischen Modernisierung zu entfliehen. Das ersehnte Hauptziel dieser Reise sollte das »ewige, unparteiische, unmoderne, tendenzlose, großartig abgethane ${ }^{116}$ Rom sein. Daß die Modernität ihn ausgerechnet in der vielleicht archaischsten Stadt Italiens, in Neapel, mit aller Macht wieder einholte, ist fast schon tragisch zu nennen.

dadurch geht der Hintere oder bei umgekehrter Stellung die Knie verloren «.

I 2 Cicerone (wie Anm. s), $368 \mathrm{ff}$.

I 3 Cicerone (wie Anm. s), Ior iff.

I 4 PA (wie Anm. 8), 207, 36e, XXX, 24.

i s Hierzu Tauber (wie Anm. 62), I9I-224.

I 6 Brief an Gottfried und Johanna Kinkel vom 9.3.1846, zwei Wochen vor Burckhardts Abreise nach Rom, Briefe (wie Anm. I), II, 2 I 2. 